\title{
A STUDY OF USING ABORTED BOVINE FETAL SKIN AND SKIN ALLOGRAFT FOR REPAIRING CRITICAL SKIN DEFECT IN DOGS
}

\author{
AHMED M.A and ALKATTAN L.M \\ Collage of Vet Med University of Mosul, Iraq.
}

Received: 30 September; Accepted: 30 October 2018

\begin{abstract}
The present study was designed to compare the potential repair efficacy of using either skin xenograft or allograft on the treatment of induced skin defects. The study was conducted on twelve stray dogs. Their weight and age ranges were $12-18 \mathrm{~kg}$ and 10-15 months, respectively. Animals were randomly allocated into two equal groups. In the first group, a $10 \mathrm{~cm}$ of full-thickness skin piece was harvested aseptically from a 4-monthaborted fetus. Along with, in the experimental animals, comparable skin defects were created at the lateral aspect of the forelimb. The grafts were fixed firmly to the wound bed by suturing. In the second group, the skin grafts $(10 \mathrm{~cm})$ were harvested from the lower abdomen of dogs and were firmly fixed over induced wounded beds at the forelimb of other dogs. In the first group, a few days postoperatively, the operative site demonstrated dryness, scar tissue formations, delayed wound healing, and local inflammation. However, after one-month post-surgery, there was a separation of the grafted tissue from the wound bed and signs of tissue rejection. In first group, histopathological examination revealed extensive infiltration of the inflammatory cells and separation of the grafted tissue from the subdermal layer. In the second group, the repaired site exhibited inflammatory signs and skin ulcers during the first postoperative week. After one month of the operation, formations of granulation tissue and restoration of normal skin coloration without hair formation were revealed on the allograft site. Complete skin healing and union of the graft with the recipient host were determined after two months of surgery. Histopathological examination demonstrated fibrocystic hyperplasia of the grafted tissue one month post-operatively, while deposition of collagen fibers was the main feature at the second month. In conclusion, unlike using of skin from the aborted bovine fetuses, the study specified the successful outcomes of using skin allograft in tissue repairing in dogs.
\end{abstract}

Key world: Xenograft, allograft, skin grafting, dog.

\section{INTRODUCTION}

Skin grafting is one of the most important techniques used for repairing of various skin defects, cosmetic purposes or restore hair growth. A variety of skin grafting techniques have been used for the treatment of critical skin loss in extremities in clinical and experimental animals (Slatter, 2003). Xenograft is another type of skin grafting in immunocompatible animal models. The main challenge faced by many researchers is the rejection and progressive loss of tissue after skin replacements. Several attempts have been made to use fresh cadaveric skin as fresh xenografts usually fresh porcine disinfected skin (Auger et al., 2009). Similar to the allograft, skin xenograft is serving as a temporary biologic dressing. Xenografts have been used extensively in covering large burnt skin parts prior to the application of autografting. In addition, Xenografts have also been used

Corresponding author: ALKATTAN L.M

E-mail address: laythalkattan@yahoo.com

Present address: Collage of Vet Med University of Mosul, Iraq. as a temporary coverage of exposed vessels, tendons, large ulcers, flap donor sites, and skin graft donor sites. (Darwish, 2011) In order to get a proper graft immobilization, vacuum-assisted closure device was utilized following skin grafting in dogs. It has been stated that this device can improve the survival rate of the utilized skin graft through superior adherence properties, serves as plasmatic imbibitions and possibly leads to revascularizations (Daniel, 2011). Temporary coverage of a wound is possible by using other grafts; such as placenta and omentum. The donor skin of an allograft (allogenic transplant or homograft) is usually obtained from an animal belonging to the same species (Tong and Simpson, 2012). The successful grafting requires asepsis, adequately prepared recipient bed consisting of healthy granulation tissue, proper harvesting of the graft, meticulous surgical technique and strict postoperative care (Siegfried et al., 2005). Several factors have been recognized to have great roles in the maintenance and survival of skin grafts; for instances, good contact between the graft and the recipient bed, normal tension on the sutured graft, strict immobilization after grafting and prevention of 
accumulation of blood or serum under the graft (Siegfried et al., 2005). The main objective of the present study is to compare the utilization of canine skin as allograft and bovine aborted fetal skin as xenograft for repairing induced skin defects in dogs.

\section{MATERIALS AND METHODS}

Twelve healthy adult mongrel dogs of both sexes were included in the present study. The animals were subdivided into two equal groups, 6 dogs each. The anesthetic protocol included the use of intramuscularly administered Xylazine $\mathrm{HCl}$ (Interchemie, Holland) and Ketamine $\mathrm{HCl}$ (Rotexmedica, Germany) at dose of $3 \mathrm{mg} / \mathrm{kg}$ and 10 $\mathrm{mg} / \mathrm{kg}$, respectively. Prior to surgery, animals of both groups were injected with a corticosteroid (Calvasone, Norbrook, England) at a dose of 0.2 $\mathrm{mg} / \mathrm{kg}$, for five consecutive days. In all groups, the distal part of the forearm was prepared aseptically by clipping and shaving of hair and application of Povidone Iodine $2.5 \%$ (Vapco, Jourdan). In the first group, a full-thickness skin graft $(10 \times 3 \mathrm{~cm})$ was harvested from a fresh bovine aborted fetus of 4 months age at the abattoir (Fig. 1). These grafts were

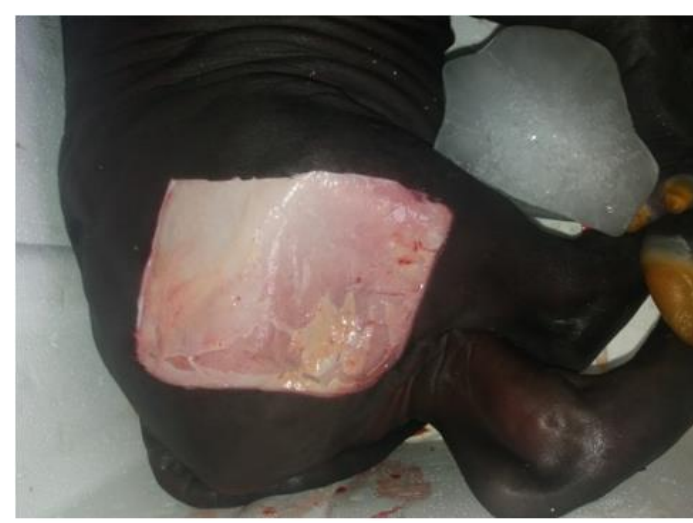

Fig. 1: Skin piece was harvested aseptically as the full thickness from an aborted fetus.

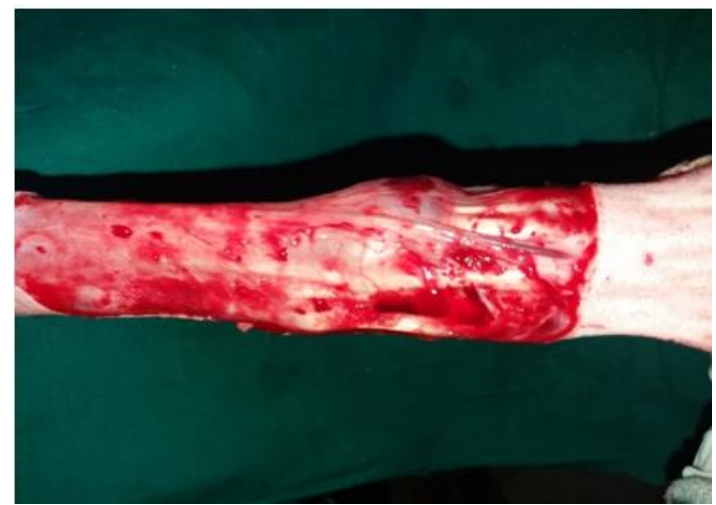

Fig. 3: Skin defect $(10 \times 3 \mathrm{~cm})$ was created at the lateral aspect of forearm. prepared for grafting by removing all fatty and underlying tissues and by inducing small holes at the skin graft (Fig. 2). At the same time, a skin defect $(10 \times 3 \mathrm{~cm})$ was induced at the lateral aspect of the forearm of the experimental animal (Fig. 3). The graft was attached firmly with the adjacent tissue and was fixed with many stitches at different sites to make it more adherent to the adjacent tissues (Fig. 4). In the second treatment group, similar steps described in the first group were followed to prepare the grafts except that the graft was harvested from a dog as a donar and implanted in another dog as a recipient (Fig. 5). The skin grafting was evaluated by macroscopic (gross) and histopathological examinations to determine efficacy of allograft and xenograft for skin reconstetruction. Tissue specimens were collected at one week, one month and two months post-operativly from the junction between the healthy and grafted tissue. Samples were fixed in $10 \%$ neutral buffered formalin for 72 hours, and then histopathological examination was performed as described by (Luna, 1968). Tissue sections were stained by Harri's Hematoxylin and alcoholic Eosin (Suvarna et al., 2013). Later, stained slides were examined using a microscope at 40X, 100X, and 400X.

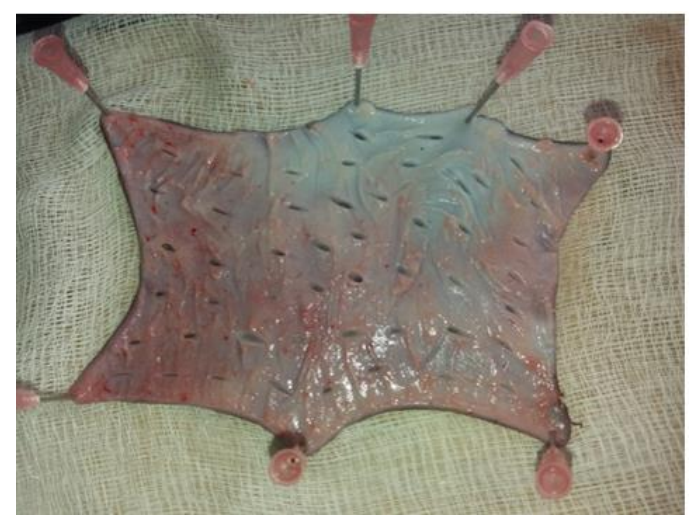

Fig. 2: Fetus skin graft prepared aseptically and small holes were made at the skin graft.

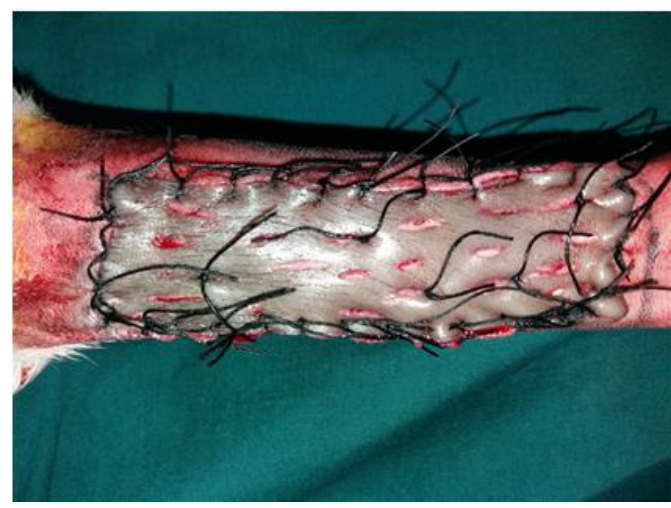

Fig. 4: Fetus skin graft was implanted firmly on the wound bed of forelimb by multiple skin sutures. 


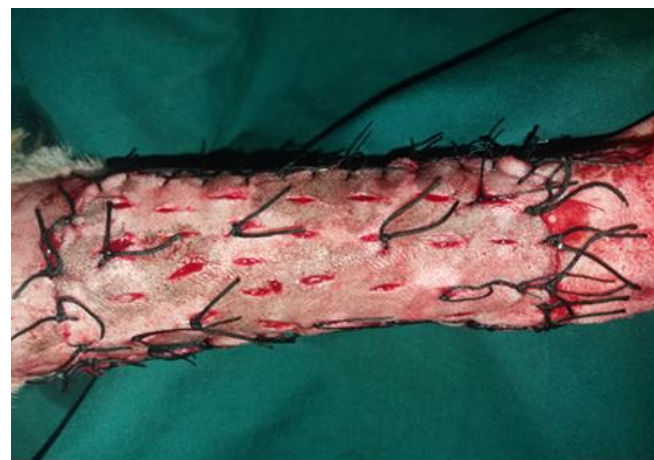

Fig. 5: Skin allograft was implanted firmly on the wound bed of forearm by multiple skin sutures.

\section{RESULTS}

During the first postoperative week, the utilized aborted fetal graft exhibited dryness, numerous scar tissue formations, delayed of wound healing, local inflammation, and wound dehiscence (Fig. 6). One month postoperatively, there was dryness, separation of grafted tissue from the wound bed and signs of tissue rejection represented by gangrenous changes in grafted tissue (Fig. 7). Histopathologically, there were extensive infiltration of inflammatory cells and separation of grafted tissue from the subdermal layer (Fig 8). One-week following surgery, gross results of

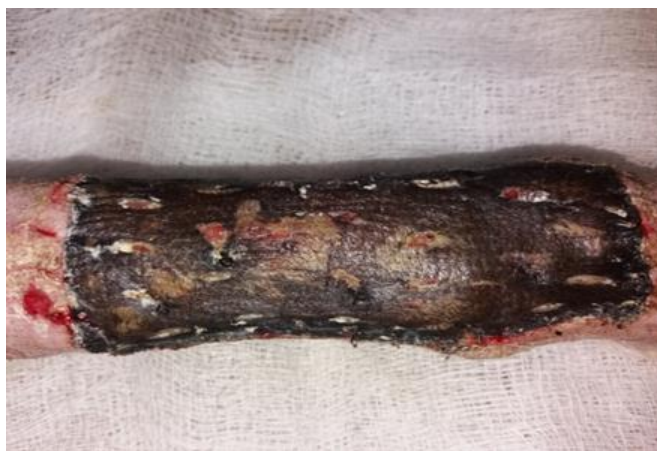

Fig. 6: Image of a xenografted dog forelimb first-week post-implantation showed dryness, numerous scar tissue formations, delayed wound healing, local inflammation and wound dehiscence

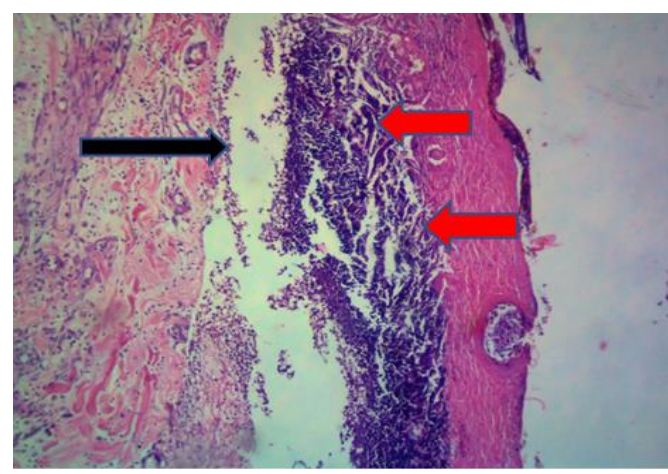

Fig. 8: Histopathological section showing an extensive infiltration of inflammatory cells (red arrows) and separation of grafted tissue from the subdermal layer (black arrow), 100x, $\mathrm{H} \& \mathrm{E}$. the second group revealed inflammatory signs, areas of hemorrhage, necrosis and skin ulcers (Fig. 9). Interestingly, one-month post-surgery, the allograft site showed the formation of granulation tissue with the restoration of normal skin color without hair formation (Fig. 10). The most interesting finding was that complete integrity of skin occurs and the graft united with recipient skin (Fig. 11). After one month, histopathological examination of the biopsies showed fibrocystic hyperplasia in the grafted tissue (Fig. 12). Whereas, after two months of surgery, deposition of sheet-like collagen fibers was dominated in the histopathological sections (Fig. 13).

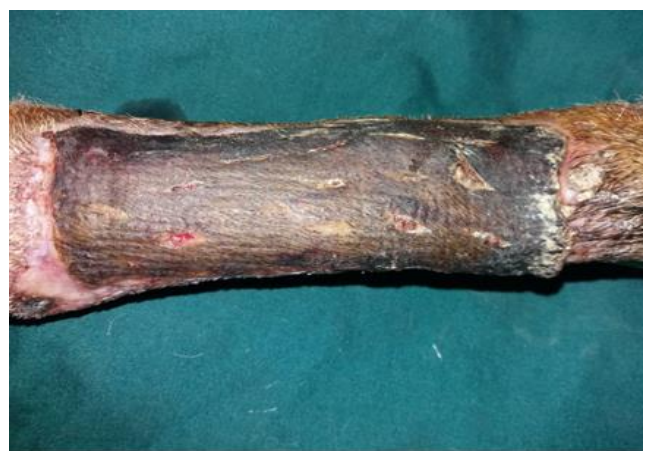

Fig. 7: Image of a xenografted dog forelimb one month post-implantation showed dryness separation of grafted tissue from the wound bed and signs of tissue rejection represented by gangrene in grafted tissue.

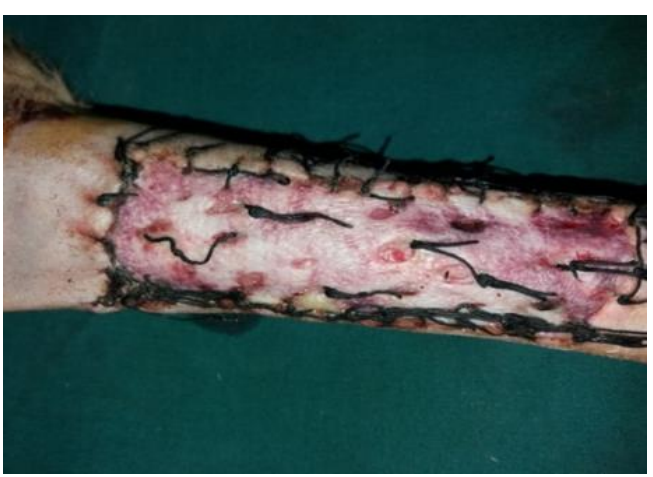

Fig. 9: One-week post-surgery, the gross image of the allografted site of dog's forelimb showing inflammatory signs, areas of hemorrhage, necrosis, and skin ulcers. 


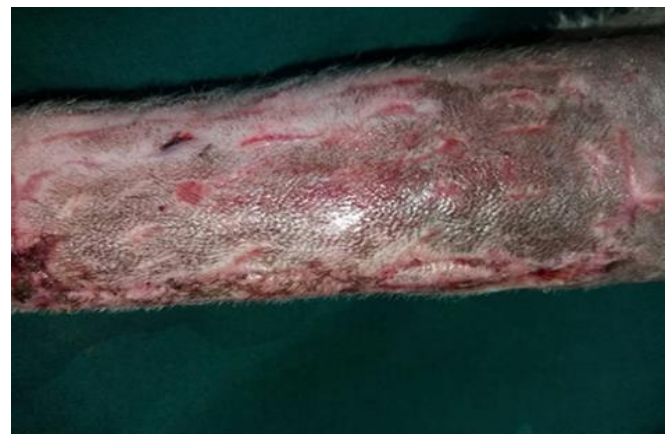

Fig. 10: One-month post-surgery, the gross image of allografted site of dog's fore limb showing the formation of granulation tissue (scar) with the restoration of normal skin color without hair formation.

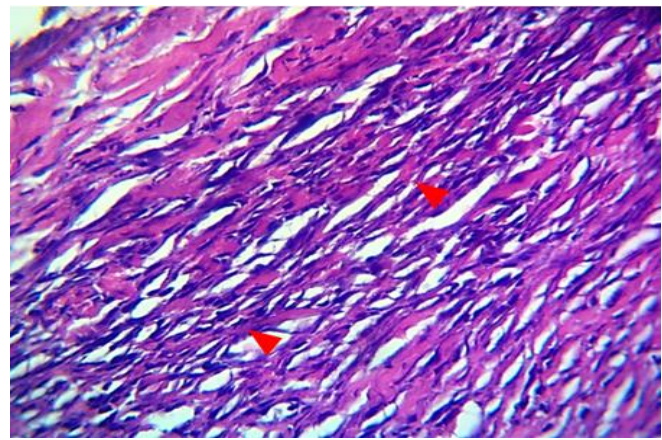

Fig. 12: Histological section of allografted site of dog's leg after one month of surgery showing fibrocystic hyperplasia in the grafted tissue (arrowhead), H\&E, 400x.

\section{DISCUSSION}

Recently, there has been a renewed interest in the treatment of serious skin injuries, which is described as a great challenging task; in particular, affections of the distal part of the limb due to the paucity of tissues (Ijaz et al., 2012). Latest advances in tissue grafting have highlighted the utilizing of skin grafts as tissue sources for reconstructive surgery. One of the key issues of grafting is the harvesting of full skin thickness from a donor to repair the site of an excised large tumor; particularly, where primary closure is not possible due to severe skin loss (Tong and Simpson, 2012). In dogs, it is an urgently required issue to address the type of skin grafting for repairing skin injuries of the extremities, where skin immobility precludes tissue shifting (Pop, 1988). In accordance with an earlier work (Rapaport, 1965), results of this study indicated the unsuccessful using of Xenograft in repairing the induced injuries after 30 days of surgery. This statement was expressed by the presence of several signs of tissue rejection. The failure of Xenografting might be explained by the lack of adequate tissue adhesions resulted in several factors; for instances, the motion of the graft over the

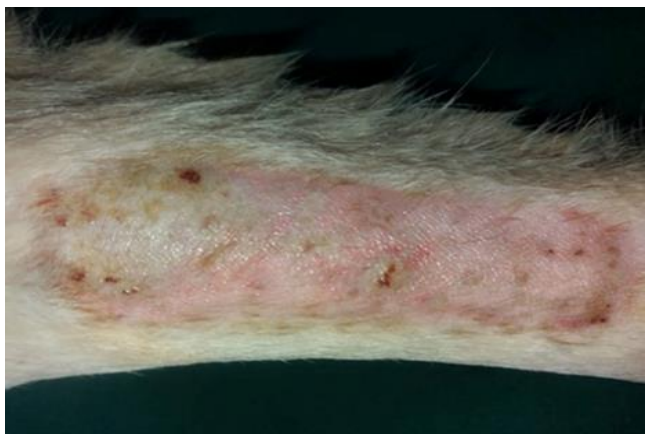

Fig. 11: Two-month post-surgery, the gross image of allografted site of dog's forelimb complete integrity of skin occurs and the graft united with recipient host with the restoration of normal skin color without hair formation.

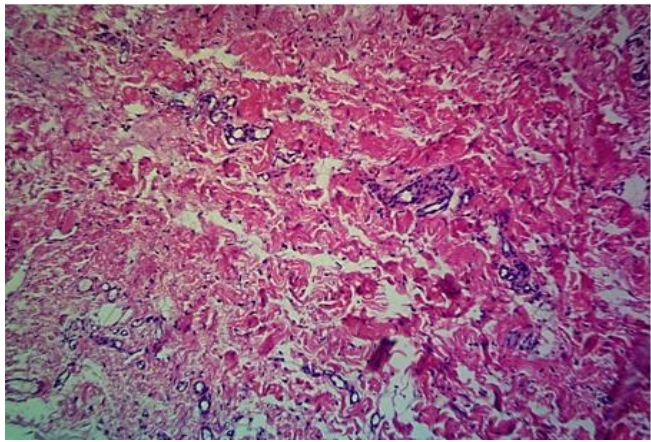

Fig. 13: Histological section of allografted site of dog's fore limb after two months of surgery showing deposition of collagen fibers as sheets as a response to granulation tissue formation, $\mathrm{H} \& \mathrm{E}, 100 \mathrm{x}$

wound surface, infection, hematoma, and presence of debris beneath the graft. This finding is in agreement with those obtained by a previous work (Pavletic, 1999). This study supports evidence from another work (Robert et al., 1983) using porcine skin grafting, where signs such as necrosis, acute inflammatory reactions, and extension of the host epithelium beneath the graft were revealed. Successful graft healing might occurs due to the establishment of adequate blood vessels and the existence of sufficient drainage (Robert et al., 1983). Vasculature at the underlying bed is expected to occur a few days postoperatively; otherwise, the graft tissue undergoes necrosis (Macphi, 2013). Thus, in our study, failure of xenografting might assign to the inadequate blood supplementation. In the first group, there was dryness, separation of the grafted tissue from the wound bed accompanied by signs of tissue rejection. Trans-dermal loss of water could be a contributing factor of tissue dryness resulting in separation of the graft from the wound bed (Kuipers et al., 2015). Rejection of the graft might also occur due to the incomplete connection between the wound surface and the graft bed, which impair the generation of blood capillaries and granulation tissue formation 
(Siegfried et al., 2005). In addition, development of a hematoma due to technical faults such as inadequate bandaging or movement of skin graft may lead to failure of tissue grafting. The development of hematoma between the graft and wound bed interrupt the required adherence and plasmatic imbibitions of the skin graft and consequently affect revascularizations of the skin graft (Pope, 1985; Swaim, 2003). Histological examination revealed an extensive infiltration of inflammatory cells and separation of grafted tissue from the subdermal layer; this may be due to the infection (Pavletic, 1999).

In our study, during the first few days, the second group manifested by adequate adherence to the wound bed accompanied with revascularization. This might be attributed to the adequate immobilization and bandaging, which provide direct connection of graft and local wound vessels and extension of vessels from the host tissue into the skin graft and/or ingrowth of host vessels into existing endothelial channels (Ijaz et al., 2012). Interestingly, histological examination of the second group showed the absence of rejection signs where the allograft tissue exhibited a normal healing process. This statement was manifested by hemostasis process inflammatory events and granulation tissue formation followed by contraction of collagen fiber around the grafted tissue. A similar observation was described (Rodero and Khosrotehrani, 2010) and concluded that such histological observations enhance both stretchings of the wound edges and initiation of the remodeling phase.

In conclusion, unlike the using of skin from the aborted bovine fetuses, the study specified the successful outcomes of using skin allograft in tissue repairing in dogs.

\section{ACKNOWLEDGEMENTS}

This study was supported by the College of Veterinary Medicine, University of Mosul, Iraq. Many thanks to assistant professor Saevan S. AlMahmood for helping in histopathological examination.

\section{REFERENCES}

Auger, D. Lacroix, L. and Germain (2009): Skin Substitutes and Wound Healing. Skin Pharmacol Physiol; 22:94-102.

Daniel, K. (2011): Advanced Course in Small Animal Soft Tissue Surgery. $1^{\text {st }}$ ed, USA. pp.8.

Darwish, A. (2011): Skin Grafts-Indications, Applications and Current Research. http://www.intechopen.com/booksMarcia S. Ed., ISBN: 978-953-307-509-9, In Tech

Ijaz, MS.; Mahmood, AK.; Ahmad, N.; Khan, MA. and Farooq, U. (2012): Viability of split thickness autogenous skin transplantation in canine distal limb reconstruction - An experimental evaluation. Pakistan Veterinary Journal; 32(2): 193-196.

Kuipers, HC.; Bremer, M.; Braem, L.; Goemanne, AS.; Middelkoop, E. and Van Loey, NE. (2015): Itch in burn areas after skin transplantation: patient characteristics, Influencing factors and therapy. Acta Dermato-venereologica 95, 451-456.

Luna, LG. (1968): Manual of Histological Staining Methods of the Army Forces Institute of Pathology Division 3rd ed. New York, USA, McGraw Hill Book Company, 1968, 12-20.

Macphil, CM. (2013): Surgery of the integumentary system. In Fossum TW, ed.: Small Animal Surgery, 4th edition: St. Louis Mosby.p.67.

Pavletic, MM. (1999): In Atlas of Small Animal Reconstructive Surgery, 2nd ed., W. B. Saunders Co. 11-32, 107-119, 131-296.

Pope, ER. (1988): Skin grafting in small animal surgery, part 1: Full-thickness skin grafting techniques. Compendium on Continuing Education for Practicing Veterinarian. 10: 915-923.

Pope, ER. (1985): Effects of skin graft preparation and graft survival on the secondary contraction of full-thickness skin grafts in dogs. American Journal of Veterinary. Research; 46: 25302535 .

Rapaport, F. (1965): In Histocompatibility Testing by Russel and Anos., 185.

Robert, S. Turnbull Ernest, E. Stross (1983): The Healing of Hamster Oral Mucosal Wounds Covered by Porcine Grafts: A Histologic Study. J Periodontol.; 54(12): 746-52.

Rodero, M. and Khosrotehrani, K. (2010): Skin wound healing modulation by macrophages Int J Clin Exp Pathol3(7): 643-53

Siegfried, R.; Schmokel, H.; Rytz, U.; Spreng, D. and Schawalder, $P$. (2005): Treatment of large distal extremity skin wounds with autogenous full-thickness mesh skin grafts in five cats. European Journal of Companion Animal Practice. 15(1): 73-78.

Slatter, DH. (2003): In Textbook of Small animal Surgery, $3^{\text {rd }}$ Edition, W B Saunders Co., Philadelphia, 321-38.

Suvarna, SK.; Layuton, C.; Bancroft, JD. and Bancroft's (2013): Theory and Practice of Histological Techniques. 7th ed New York, USA: Churchill Livingstone Press, 2013, pp. 12-32.

Swaim, SF. (2003): Skin grafts, In Slatter (Ed): Textbook of Small Animals Surgery, Ed 3. Philadelphia, WB Saunders, PP 321-338.

Tong, T. and Simpson, DJ. (2012): Free skin grafts for immediate wound coverage following tumor resection from the canine distal limb. J Small Anim Pract; 53(9): 520-525. 


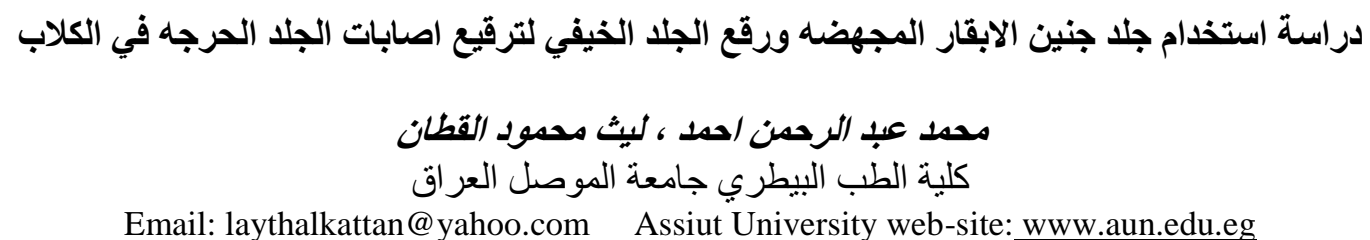

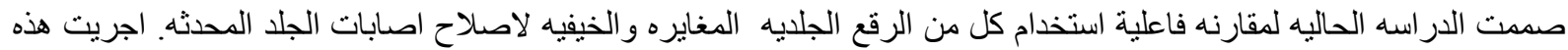

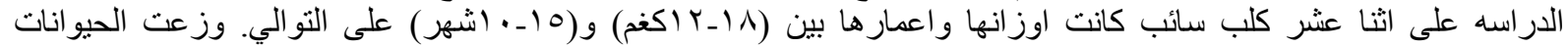

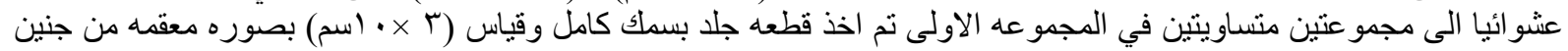

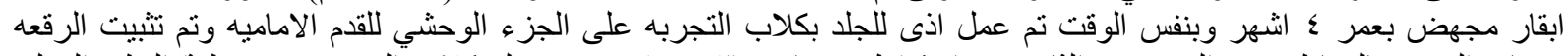

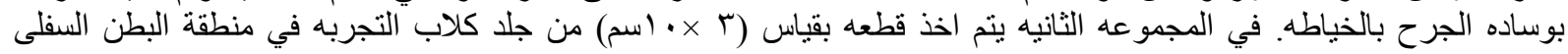

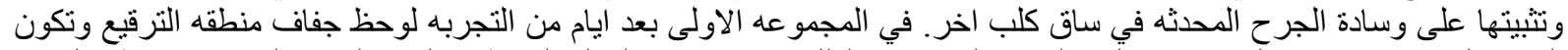

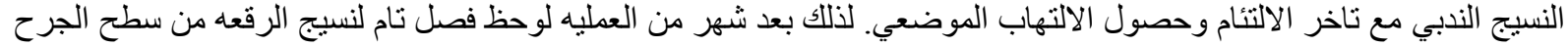

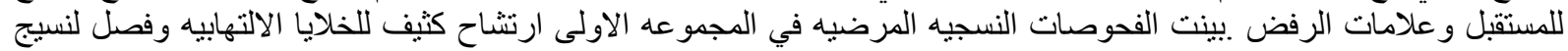

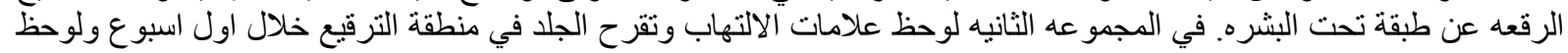

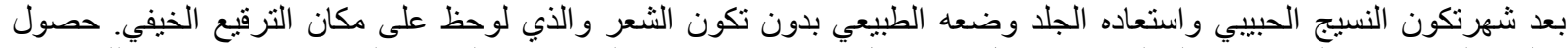

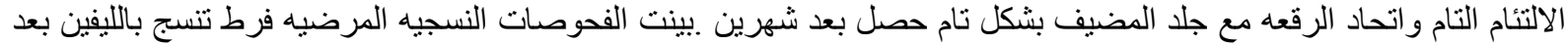
شهر من الترقيع بينما كان ترسب الالياف الكو لاجينيه الغالب بعد شهرين من العمليه. خلاصة العمل العام ان استخدام جلد جنين الابقار

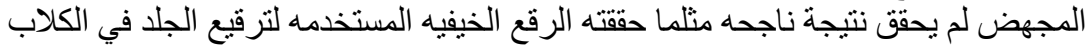

